\title{
Low Blood Levels of Long-Chain n-3 Polyunsaturated Fatty Acids in US Hemodialysis Patients: Clinical Implications
}

\author{
Allon N. Friedman ${ }^{\mathrm{a}}$ Zhangsheng Yu ${ }^{\mathrm{b}}$ Rebeka Tabbey ${ }^{\mathrm{b}}$ Cheryl Denski ${ }^{\mathrm{b}}$ \\ Hector Tamez $^{c}$ Julia Wenger ${ }^{c}$ Ravi Thadhani ${ }^{c}$ Yong Li ${ }^{d}$ Bruce A. Watkins ${ }^{d}$ \\ a Department of Medicine, Division of Nephrology, Indiana University School of Medicine, \\ ${ }^{b}$ Department of Biostatistics, Indiana University School of Medicine, Indianapolis, Ind, \\ 'Department of Medicine, Division of Nephrology, Massachusetts General Hospital, Boston, Mass., and \\ ${ }^{\mathrm{d}}$ Department of Nutritional Sciences, Lipid Chemistry and Molecular Biology Laboratory, University of Connecticut, \\ Storrs, Conn., USA
}

\section{Key Words}

Omega-3 · Fatty acids · Hemodialysis • Cardiovascular $\cdot$ Nutrition

\begin{abstract}
Background: Cardioprotective and other clinical benefits of long-chain $n-3$ polyunsaturated fatty acids (PUFA) are inversely related to dietary intake and hence blood content. We therefore investigated, in the first study of its kind, the blood content and distribution of these fatty acids in a large representative population of US hemodialysis patients. Methods: Frozen sera were obtained from 400 individuals who were part of a large, contemporary, representative cohort of US incident hemodialysis patients. Long-chain $n-3$ PUFA were measured in total serum lipids and in the neutral and polar serum fractions using gas chromatography and solid phase extraction techniques. Mean long-chain n-3 PUFA levels were compared to levels in other dialysis and nondialysis populations from published reports. Results: The study population was qualitatively similar to the overall US hemodialysis population in terms of major clinical characteristics. Long-chain n-3 PUFA were present in the serum polar fraction, with essentially none being detected in the neutral fraction ( $p<0.0001$ for polar vs. neutral fractions for
\end{abstract}

all three long-chain n-3 PUFA). Mean serum long-chain $n-3$ PUFA levels (weight percent $( \pm S D$ ): total $1.55 \pm 0.95$, polar $3.99 \pm 1.45$ ) were low compared to nondialysis and most other non-US hemodialysis cohorts. Conclusions: While US hemodialysis patients have a blood distribution of longchain n-3 PUFA that is similar to that in the general population, blood content is among the lowest recorded in the medical literature. This has implications for renal dietary recommendations and makes US patients an ideal group for testing the clinical effects of long-chain n-3 PUFA supplementation.

Copyright $\odot 2012$ S. Karger AG, Basel

\section{Introduction}

Long-chain n-3 polyunsaturated fatty acids (PUFA) mediate a number of key biologic processes including eicosanoid production, cell membrane physiology, and signaling pathways, inflammation, and gene regulation and expression [1-3]. Observational and interventional studies have in recent years raised the possibility that long-chain n-3 PUFA may also offer clinical benefits to hemodialysis patients in such areas as dialysis access patency, cardiovascular health, and mortality [4-7].

\section{KARGER}

Fax +41613061234 E-Mail karger@karger.ch www.karger.com

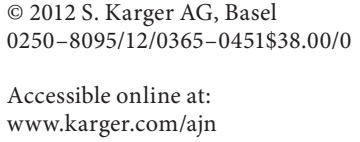


Yet relatively little is known about the content of serum or plasma long-chain n-3 PUFA in hemodialysis patients, especially in comparison to other populations. The existing literature is comprised of a few modestly sized studies, mostly performed outside the USA [8-13]. Longchain n-3 PUFA content in blood is important to define because it helps determine the benefits of long-chain $n-3$ PUFA supplementation on clinical outcomes. Populations with lower dietary intake of long-chain n-3 PUFA - and subsequently lower blood levels - are much more likely to reap the clinical benefits of supplementation than groups with higher baseline consumption [14]. In addition, quantifying long-chain n-3 PUFA content will help inform future dietary intake recommendations for hemodialysis patients.

The distribution of long-chain n-3 PUFA and other fatty acids in the blood of hemodialysis patients has also been understudied. In nondialysis patients, blood fatty acids are distributed between neutral (triglyceride, cholesterol esters) and polar (phospholipid) fractions, with the majority of long-chain n-3 PUFA accumulating in the polar fraction [15]. A better understanding of the distribution of long-chain n-3 PUFA in the blood of hemodialysis patients will provide important insights into the lipid metabolism of that population as well as guide future biomarker selection.

In the first such study of its kind to date, we measured the content and distribution of long-chain n-3 PUFA and other important fatty acids in the serum of a large representative cohort of US patients who recently initiated hemodialysis, and then compared levels to other published cohorts. We hypothesized that long-chain n-3 PUFA content would be low relative to other populations but distributed in a similar manner in the blood.

\section{Methods}

Study Population and Collection of Serum Samples

All study subjects participated in the Accelerated Mortality on Renal Replacement (ArMORR) project, a nationally representative prospective cohort study of patients who initiated chronic hemodialysis at any one of over 1,000 US dialysis centers operated by Fresenius Medical Care, North America. Between July 1, 2004, and June 30,2005, 10,044 incident hemodialysis patients representing 1,056 US dialysis units were prospectively enrolled into ArMORR. ArMORR contains detailed demographic and clinical data, including comorbid conditions, laboratory results, and blood samples at time of dialysis initiation. All clinical data were collected prospectively and entered uniformly into a central database by the patients' practitioners at the point-of-care based on medical records and physical examination. All clinical data points arriving at Fresenius underwent rigorous quality assurance/quality control auditing because these data are directly linked to Medicare billing services, and routine quality assurance/quality control measures are mandated by the Clinical Quality Group and Data Entry Error Reduction Task Force at Fresenius. Blood samples collected for clinical care were drawn at individual dialysis units and shipped the same day on ice to Spectra East (Rockland, N.J., USA), a good clinical practice-accredited central laboratory. Study subjects' blood samples were individually labeled with a yellow sticker, thus notifying technicians of the need to handle these samples especially expeditiously. Samples were not sent from Friday or Saturday dialysis sessions to ensure that all samples were processed immediately. If samples were not received on ice or contained insufficient quantities of blood, they were not included in the ArMORR study. After blood was extracted for clinical testing, the remaining serum was immediately placed in new tubes and frozen at $-80^{\circ} \mathrm{C}$. They were then sent in batches on dry ice to the ArMORR investigators where the samples were aliquoted and immediately stored at $-80^{\circ} \mathrm{C}$ (and subsequently liquid nitrogen). Because many aliquots were available for each study subject, the need to expose samples to multiple freeze/thaw cycles was avoided. This study was approved by the Institutional Review Board of the Massachusetts General Hospital (Boston, Mass., USA), which waived the need for informed consent. The $400 \mathrm{Ar}-$ MORR subjects used for this analysis were part of a separate study that included 100 patients who died of sudden cardiac death during the first year on hemodialysis and 300 patients who survived. The results of that analysis will be published separately.

\section{Laboratory Analysis}

Biochemical assays were performed at Spectra East Laboratory as previously described using standard assays. Serum was used to determine fatty acid amounts in various lipid fractions in blinded fashion at the University of Connecticut: $100 \mu \mathrm{l}$ was used for the total lipid analysis and $140 \mu \mathrm{l}$ for the neutral and polar lipid fraction analyses. Serum lipids were extracted with chloroform/ methanol $(2: 1, \mathrm{vol} / \mathrm{vol})$. For the analysis of fatty acids in the neutral and polar lipid fractions, solid phase extraction was used to fractionate the extracted lipids with chloroform eluting the neutral lipid fraction and the methanol eluting the polar lipid fraction by a silica cartridge (300 mg filling, Alltech) [16]. For the measurement of fatty acids in total lipids and neutral lipid fraction, the extracted lipids were treated with $0.5 \mathrm{~N} \mathrm{NaOH}$ in methanol, and fatty acid methyl esters (FAME) prepared by esterification using boron trifluoride (BF3) in methanol (10\% w/w, Supelco Inc., Bellefonte, Pa., USA). The polar lipids fraction was methylated to FAME directly with $10 \% \mathrm{BF} 3$ in methanol. The resulting FAME from the total, neutral, and polar fractions were concentrated in isooctane (HPLC grade, Fisher Scientific, Pittsburg, Pa., USA) and analyzed by gas chromatography (HP 7890A series, autosampler 7693, gas chromatography ChemStation Rev.B.04.03; Agilent Technologies, Palo Alto, Calif., USA) with a DB-225 column (30 m, 0.25 mm i.d., 0.15-mm film thickness; Agilent Technologies) equipped with a flame ionization detector [16]. Sample peaks were identified by comparison to authentic FAME standards (NuChek-Prep Inc., Elysian, Minn., USA). Results of FAME analysis were obtained by area percentage reports and reported in weight percent. Long-chain n-3 PUFA were defined as the area percent of 20:5n-3 (eicosapentaenoic acid) + 22:5n-3 (docosapentaenoic acid) $+22: 6 n-3$ (docosahexaenoic acid), and long-chain n-6 
PUFA as the area percent of 20:4n-6 (arachidonic acid) $+22: 4 n-6$ $+22: 5 n-6$.

\section{Statistical Analysis}

Baseline characteristics were summarized by means \pm SD for continuous variables and frequency for categorical variables. Summary statistics (median, 25th, 75th percentile) for each fatty acid (expressed as percentage of total fatty acid weight) were performed for each of the total, neutral, and polar fatty acid fractions. Percentages of neutral and polar fatty acid were compared using a Wilcoxon signed-rank test due to their skewed distribution. Ninety-five percent confidence intervals for mean long-chain n-3 fatty acids were constructed and plotted for comparison to other populations. All statistical tests were performed at a two-sided 5\% type I error rate using the SAS 9.3 software package (Cary, N.C., USA).

\section{Results}

Baseline characteristics of the 400-patient cohort are described in table 1 . The study cohort was highly representative of the overall US hemodialysis population [17] in terms of age (study cohort vs. US population: 66 vs. 63 years), gender ( 58 vs. $56 \%$ male), race ( 31 vs. $32 \%$ black), ethnicity (12 vs. 13\% Hispanic), mean BMI (26 vs. $29 \mathrm{~kg} /$ $\mathrm{m}^{2}$ ), cause of end-stage renal disease ( $47 \mathrm{vs.} 45 \%$ due to diabetes), and initial type of vascular access ( 55 vs. $63 \%$ starting with dialysis catheter).

Fatty acids measured in the total serum and neutral and polar serum fractions are shown in table 2. In total serum, the most abundant fatty acids were, in descending order, linoleic acid (18:2n-6), oleic acid (18:1n9), and palmitic acid (16:0). All three long-chain n-3 PUFA were clearly identifiable in the serum polar fraction, with docosahexaenoic acid (22:6n-3) and docosapentaenoic acid (22:5n-3) being the most abundant, while essentially none were detected in the neutral fraction $(\mathrm{p}<0.0001$ for amounts of each long-chain $n-3$ fatty acid in the polar vs. neutral fractions). Long-chain $\mathrm{n}-6$ fatty acids followed a similar pattern, with arachidonic acid (20:4n-6) accumulating to a much greater extent in the serum polar fraction ( $p<0.0001)$. However, the ratio of long-chain n-6:n-3 PUFA acids was lower in the polar fraction, reflecting a preferential integration of long-chain n-3 to long-chain n-6 PUFA in the phospholipids that comprise the polar fraction $(\mathrm{p}<0.0001)$.

Figure 1 shows a qualitative comparison between mean serum and plasma polar long-chain n-3 PUFA in our study cohort [mean in total serum by weight percent (95\% CI): $2.15(2.06,2.24)$, and in polar fraction: 3.99 $(3.85,4.13)]$ versus other diverse nondialysis and hemodi-
Table 1. Baseline characteristics

\begin{tabular}{|c|c|}
\hline & $\begin{array}{l}\text { Study population } \\
(\mathrm{n}=400)\end{array}$ \\
\hline Age, years & $66.4 \pm 14.1$ \\
\hline Male, n (\%) & $232(58.0)$ \\
\hline \multicolumn{2}{|l|}{ Race, n (\%) } \\
\hline Black & $124(31.0)$ \\
\hline White & $272(68.0)$ \\
\hline Other & $4(1.0)$ \\
\hline \multicolumn{2}{|l|}{ Ethnicity, n (\%) } \\
\hline Non-Hispanic & $352(88)$ \\
\hline Hispanic & $48(12)$ \\
\hline BMI & $26.2 \pm 6.8$ \\
\hline \multicolumn{2}{|l|}{ Cause of end-stage renal disease, $\mathrm{n}(\%)$} \\
\hline Diabetes & $186(46.5)$ \\
\hline Other & $214(53.5)$ \\
\hline \multicolumn{2}{|l|}{ Comorbidities, n (\%) } \\
\hline Hypertension & $149(37.3)$ \\
\hline $\begin{array}{l}\text { Coronary artery disease/ } \\
\text { myocardial infarction }\end{array}$ & $46(11.5)$ \\
\hline Peripheral vascular disease & $20(5.0)$ \\
\hline Congestive heart failure & $50(12.5)$ \\
\hline Atrial fibrillation & $13(3.3)$ \\
\hline Stroke & $15(3.8)$ \\
\hline \multicolumn{2}{|l|}{ Initial type of vascular access, $n(\%)$} \\
\hline First access fistula & $120(31.1)$ \\
\hline First access graft & $44(14.3)$ \\
\hline First access catheter & $211(54.7)$ \\
\hline Systolic BP, mm Hg & $142.8 \pm 23.0$ \\
\hline Diastolic BP, mm Hg & $72.6 \pm 12.4$ \\
\hline \multicolumn{2}{|l|}{ Medications, n (\%) } \\
\hline ACE inhibitor or ARB & $169(42.3)$ \\
\hline$\beta$-Blocker & $243(60.8)$ \\
\hline Aspirin & $129(32.3)$ \\
\hline Statin & $159(39.8)$ \\
\hline \multicolumn{2}{|l|}{ Predialysis laboratory values } \\
\hline Serum albumin, g/dl & $3.5 \pm 0.5$ \\
\hline Serum cholesterol, mg/dl & $150.6 \pm 46.0$ \\
\hline Serum creatinine, $\mathrm{mg} / \mathrm{dl}$ & $6.1 \pm 2.6$ \\
\hline Serum ferritin, $\mathrm{ng} / \mathrm{ml}$ & $328.3 \pm 583.2$ \\
\hline Serum phosphorus, mg/dl & $4.6 \pm 1.6$ \\
\hline Serum potassium, $\mathrm{mEq} / 1$ & $4.3 \pm 0.6$ \\
\hline Serum calcium, mg/dl & $8.4 \pm 0.8$ \\
\hline Serum PTH, pg/ml & $263.1 \pm 299.4$ \\
\hline Serum alkaline phosphatase, units/l & $100.3 \pm 71.3$ \\
\hline Serum glucose, $\mathrm{mg} / \mathrm{dl}$ & $157.8 \pm 78.5$ \\
\hline Hemoglobin, g/dl & $10.3 \pm 1.4$ \\
\hline White blood cells, $\times 10^{3} / \mu \mathrm{l}$ & $8.4 \pm 3.3$ \\
\hline Standardized Kt/V & $1.2 \pm 0.4$ \\
\hline
\end{tabular}

Values are means \pm SD unless otherwise indicated. 
Table 2. Distribution of serum total, neutral, and polar fatty acids ${ }^{1}$

\begin{tabular}{|c|c|c|c|c|}
\hline Fatty acid & Total & Neutral & Polar & $\mathrm{p}$ value ${ }^{2}$ \\
\hline \multicolumn{5}{|l|}{ Saturated } \\
\hline $16: 0$ & $20.2(19.2,21.4)$ & $17.8(16.4,19.5)$ & $22.6(21.1,23.8)$ & $<0.0001$ \\
\hline $18: 0$ & $6.8(6.2,7.5)$ & $4.4(3.6,5.1)$ & $17.6(15.9,19.3)$ & $<0.0001$ \\
\hline \multicolumn{5}{|l|}{ Monounsaturated } \\
\hline $16: 1 \mathrm{n}-7$ & $2.3(2.2,2.6)$ & $2.4(1.2,2.4)$ & $2.4(2.2,2.6)$ & $<0.0001$ \\
\hline $18: 1 n-9$ & $23.9(21.7,26.2)$ & $28.1(26.1,31.2)$ & $15.6(13.5,17.9)$ & $<0.0001$ \\
\hline $18: 1 n-7$ & $2.3(2.2,2.6)$ & $2.1(1.9,2.4)$ & $2.4(2.2,2.6)$ & $<0.0001$ \\
\hline \multicolumn{5}{|l|}{ Polyunsaturated } \\
\hline \multicolumn{5}{|l|}{ Omega-6 } \\
\hline $18: 2 n-6$ & $28.3(26.4,30.8)$ & $33.3(29.8,37.3)$ & $18.7(16.7,20.6)$ & $<0.0001$ \\
\hline $20: 4 n-6$ & $7.5(6.0,9.0)$ & $5.1(3.8,6.5)$ & $10.5(8.8,12.1)$ & $<0.0001$ \\
\hline \multicolumn{5}{|l|}{ Omega-3 } \\
\hline $18: 3 n-3$ & $0.5(0.4,0.7)$ & $0.0(0.0,0.8)$ & $0.3(0.3,0.5)$ & 0.0092 \\
\hline $20: 5 n-3$ & $0.3(0.2,0.4)$ & $0.0(0.0,0.0)$ & $0.3(0.2,0.4)$ & $<0.0001$ \\
\hline $22: 5 n-3$ & $0.4(0.3,0.5)$ & $0.0(0.0,0.0)$ & $0.8(0.6,0.9)$ & $<0.0001$ \\
\hline $22: 6 n-3$ & $1.3(1.0,1.8)$ & $0.0(0.0,0.4)$ & $2.8(2.2,3.4)$ & $<0.0001$ \\
\hline Long-chain n-3 & $2.0(1.6,2.5)$ & $0.0(0.0,0.4)$ & $3.8(3.1,4.5)$ & $<0.0001$ \\
\hline Long-chain n-6 & $8.0(6.5,9.7)$ & $5.1(3.8,6.5)$ & $11.4(9.7,13.1)$ & $<0.0001$ \\
\hline Long-chain $n-6 / n--3$ & $4.0(3.3,4.7)$ & $8.7(6.0,10.6)$ & $3.0(2.6,3.5)$ & $<0.0001$ \\
\hline Saturated fatty acids & $28.0(26.8,29.2)$ & $22.4(20.7,24.6)$ & $40.9(39.2,42.7)$ & $<0.0001$ \\
\hline Monounsaturated fatty acids & $28.2(25.5,30.8)$ & $32.8(29.7,36.1)$ & $19.1(16.6,21.6)$ & $<0.0001$ \\
\hline Polyunsaturated fatty acids & $40.9(38.0,44.3)$ & $39.3(35.2,43.8)$ & $36.9(34.6,38.9)$ & $<0.0001$ \\
\hline
\end{tabular}

${ }^{1}$ Median (25th, 75th percentiles) of percent weight.

${ }^{2}$ Wilcoxon signed rank test for comparison between neutral and polar fractions.

alysis populations published within the last three decades [8-10, 18-25]. The spread between populations was wide and encompassed a range between 2 and 12 mean weight percent. Compared to nondialysis populations, hemodialysis patients had mean levels that were on the low end of the spectrum. Compared to other hemodialysis cohorts, mean levels in US patients (i.e. our cohort) were among the lowest. A similar construct for serum or plasma total long-chain n-3 PUFA is presented in figure 2, where the spread is not nearly as great [11-13, 26-28]. Here as well, hemodialysis patients had in general lower levels than nondialysis patients, with US patients having the lowest mean levels overall.

\section{Discussion}

Our study found that long-chain n-3 PUFA in hemodialysis patients are preferentially distributed in the polar fraction of serum, similar to what is seen in the general population, but that overall blood content was low com- pared to other cohorts reported in the medical literature. These findings have implications in the areas of lipid metabolism related to health and disease, biomarker selection, and dietary recommendations for US hemodialysis patients.

Fatty acid content of blood and tissues can be used as a biomarker of dietary intake [29]. We observed the most abundant fatty acids in the serum to be linoleic, oleic, and palmitic fatty acids, similar to what is seen in the general population [29] and a reflection of the abundant dietary intake of cooking oils and processed foods that contain these fatty acids. Within the serum (or plasma), fatty acids are found in nonesterified form (typically bound to albumin), in triglycerides and cholesterol esters (neutral fraction), or in phospholipids (polar fraction). In healthy individuals, long-chain n-3 PUFA comprise only a tiny proportion $(1-3 \%)$ of the total fatty acids and are contained primarily in the polar fraction (phospholipids) [15]. Again, this is consistent with what we observed in our hemodialysis cohort, suggesting that the presence of kidney failure does not alter how fatty acids are distrib- 


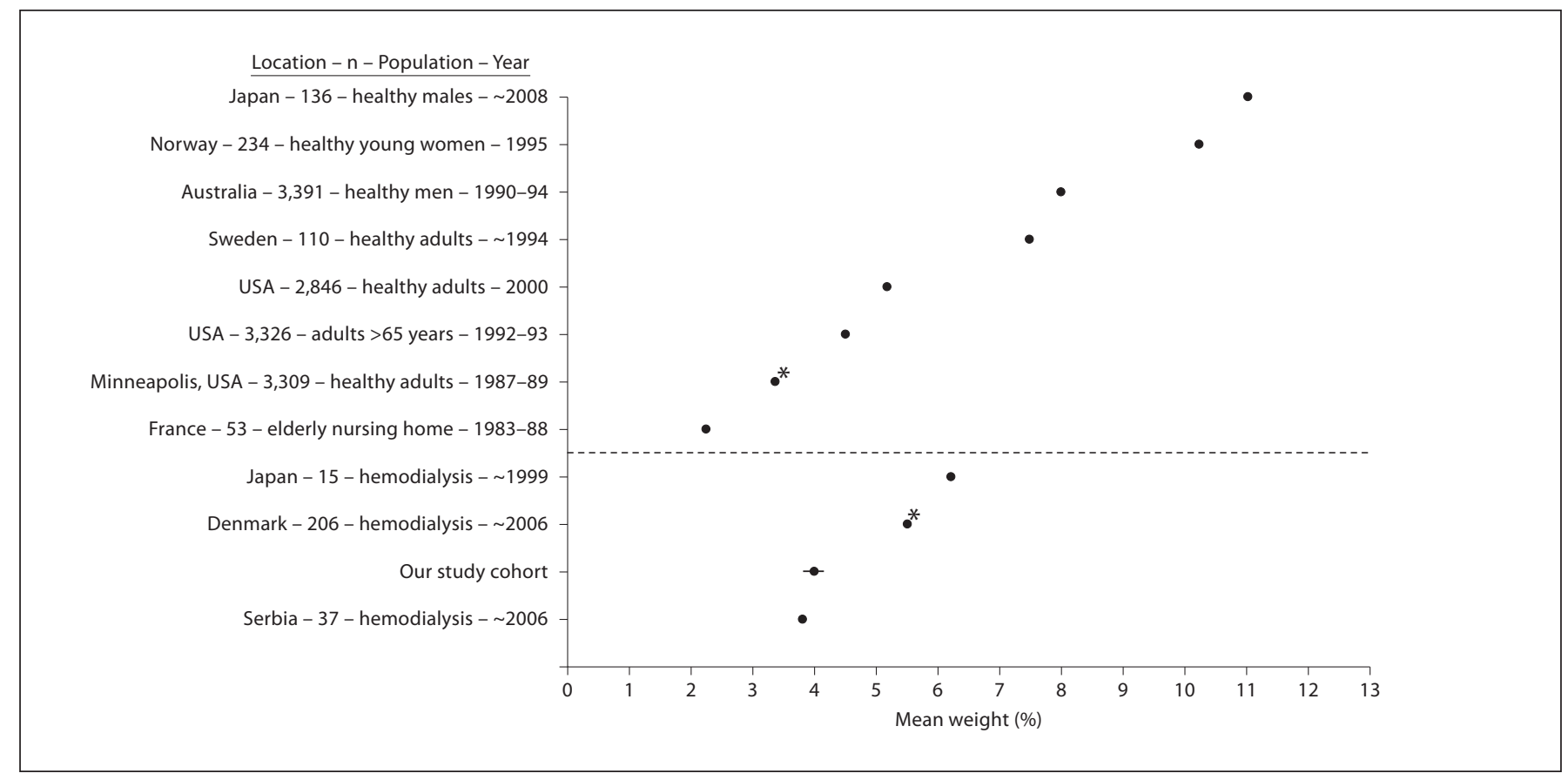

Fig. 1. Comparison of mean serum or plasma phospholipid long-chain n-3 fatty acids in ascending order (left to right) between our study cohort and other published cohorts. Nondialysis and hemodialysis populations are shown above and below the dotted line, respectively. The 95\% CI for our study cohort is displayed by the dark line through the mean. ${ }^{*}$ Includes only eicosapentaenoic acid + docosahexaenoic acid.

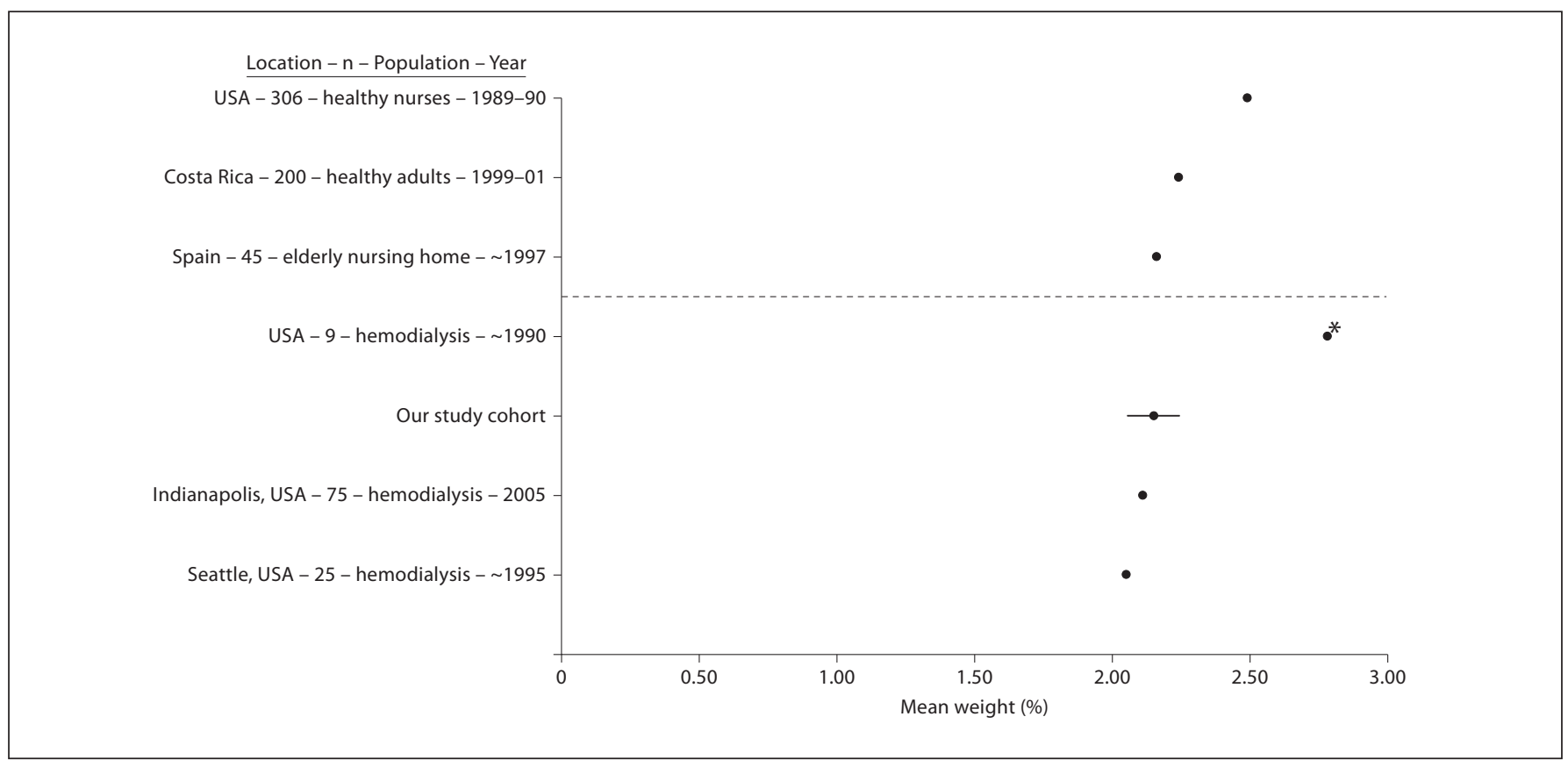

Fig. 2. Comparison of mean serum or plasma total long-chain $n-3$ fatty acids in ascending order (left to right) between our study cohort and other published cohorts. Nondialysis and hemodialysis populations are shown above and below the dotted line, respectively. The 95\% CI for our study cohort is displayed by the dark line through the mean. ${ }^{*}$ Includes only eicosapentaenoic acid + docosahexaenoic acid. 
uted, at least within the blood. Because very few, if any, long-chain n-3 PUFA accumulate in the neutral fraction, it is reasonable to conclude that as with individuals not on dialysis, only serum total or polar long-chain $n-3$ PUFA will be useful as biomarkers in hemodialysis patients.

Long-chain n-3 PUFA are obtained primarily from dietary fish consumption or supplements, which contains far greater amounts than other foodstuffs [30]. While it is well established that consuming more dietary long-chain n-3 PUFA increases the proportion present in blood [29], there is scant information on the amount of dietary long-chain n-3 PUFA consumed by hemodialysis patients. We previously reported that among American Midwesterners, two thirds of hemodialysis patients consume 1 or less servings of fish per week [11], far below the guidelines established by the American Heart Association [30]. A more recent report using a validated nutritional survey in coastal US hemodialysis patients found the median dietary intake for all $\mathrm{n}-3$ fatty acids [including the 18-carbon $\alpha$-linolenic acid (18:3n-3)] to be 1.1 g/day (25-75th percentile: 0.8-1.6) [31], lower than the 1.6 $\mathrm{g} /$ day reported in the US general population [32]. In the general populace, only $0.1-0.2 \mathrm{~g} /$ day of the total $\mathrm{n}-3$ PUFA intake is derived from long-chain n-3 PUFA, so it can reasonably be expected that hemodialysis patients consume even less than this amount. Our findings confirm this suspicion. We observed that hemodialysis patients as a population had serum long-chain n-3 levels that were at the lowest end of the spectrum when compared to nondialysis populations. Moreover, US hemodialysis patients had levels that were not only among the very lowest recorded overall, but also had far lower levels than hemodialysis patients in Japan or Scandinavia, where seafood comprises a larger part of the diet.

Why is this important? As Mozaffarian and Rimm [14] have demonstrated, reduction of cardiovascular death risk with n-3 PUFA supplementation is greatest in populations where dietary intake and blood levels of long-chain n-3 PUFA are lowest. This is particularly true for the putative antiarrhythmic effects of long-chain $n-3$ PUFA, a salient issue given that sudden cardiac death is the most common cause of death in hemodialysis patients [33]. In fact, data are accumulating in the hemodialysis population to suggest that long-chain n-3 PUFA may provide cardioprotective and survival benefits [4-7, 31], though not all studies are in agreement [34]. What may explain the varying results between studies that supplemented dialysis patients with fish oil are baseline longchain n-3 PUFA levels, which were much higher in the negative [34] than positive [4-7, 31] trials, consistent with the premise of Mozaffarian and Rimm. Other benefits such as improved hemodialysis access patency, blood pressure, lipid profile, and inflammatory status may also accrue from increased dietary long-chain n-3 PUFA consumption $[4,35]$. In light of our findings, the US hemodialysis population appears to be an exceptionally good cohort in which to study the clinical benefits of longchain n-3 PUFA supplementation.

Currently, there are no renal dietary recommendation guidelines for long-chain n-3 PUFA consumption, although recent National Kidney Foundation Disease Outcomes Quality Initiative (NKF KDOQI) guidelines state that 'studies are required to identify the essential fatty acid status of CKD patients...' [36]. Our findings provide compelling evidence that, particularly in light of their heavy burden of illness, renal dietary guidelines should be re-evaluated to address the need to recommend greater dietary long-chain n-3 PUFA intake in US hemodialysis and possibly other similar populations.

Our study does have limitations. The 400 -subject cohort was not a random sampling of the larger 10,000 patient nationally representative cohort from which it was derived. However, as we observed, it was very similar to the greater US hemodialysis population in terms of the most important clinical characteristics. Our cohort was also comprised entirely of US incident patients, so we cannot automatically extrapolate our findings to prevalent patients, though the prevalent US cohorts included in figure 2 reported results similar to ours. Measuring fatty acids in erythrocytes or adipose tissue would have provided additional useful information, but no such samples were available for measurement. Though our comparison of mean long-chain n-3 PUFA levels (fig. 1, 2) included information from every available published hemodialysis cohort, the size and diversity of these cohorts were still somewhat limited. Also, the healthy cohorts were not specifically matched to our or other hemodialysis patient cohorts. While variations in the methods used to measure long-chain n-3 PUFA levels could conceivably have explained some of the differences between our and other cohorts, results from other US hemodialysis cohorts studied at different times and locations support our findings.

Our study also has a number of strengths. This was the largest and most rigorous study to date characterizing serum fatty acids in general, and long-chain n-3 PUFA in particular, in the hemodialysis population. The fact that our study patients were initiating hemodialysis offers new and useful information at a time point during which 
patient risk for hospitalization and death is at its highest [37], and which is of tremendous interest to the nephrology community and dialysis providers.

In conclusion, while the distribution of long-chain $n-3$ PUFA in the serum of US incident hemodialysis patients was similar to that observed in the general population, actual blood content was very low, especially in light of the putative benefits of higher levels. This finding supports the reassessment of current renal dietary intake guidelines and also suggests that hemodialysis patients are an ideal group in which to test the effects of longchain n-3 PUFA supplementation.

\section{Acknowledgements}

A.N.F. and B.A.W. were supported by funding from the National Institutes of Health (DK084403) and the National Kidney Foundation. R.T. is supported by funding from the National Institutes of Health (DK094872, HL112746). Some of the data described herein were presented at the 2012 International Society for Renal Metabolism and Nutrition meeting.

\section{Disclosure Statement}

R.T. is a consultant to Fresenius Medical Care North America.

\section{References}

$\checkmark 1$ Oh DY, Talukdar S, Bae EJ, Imamura T, Morinaga H, Fan W, Li P, Lu WJ, Watkins SM, Olefsky JM: Gpr120 is an omega-3 fatty acid receptor mediating potent anti-inflammatory and insulin-sensitizing effects. Cell 2010;142:687-698

-2 Serhan CN, Savill J: Resolution of inflammation: the beginning programs the end. Nat Immunol 2005;6:1191-1197.

-3 Borkman M, Storlien LH, Pan DA, Jenkins $\mathrm{AB}$, Chisholm DJ, Campbell LV: The relation between insulin sensitivity and the fatty-acid composition of skeletal-muscle phospholipids. New Engl J Med 1993;328:238-244.

4 Lok C, Moist L, Hemmelgarn B, tonelli M, Vazquez M, Dorval M, Oliver M, Donnelly S, Allon M, Stanley K: Effect of fish oil supplementation on graft patency and cardiovascular events among patients with new synthetic arteriovenous hemodialysis grafts. JAMA 2012;307:1809-1816.

$\checkmark 5$ Friedman AN, Saha C, Watkins BA: Feasibility study of erythrocyte long-chain omega-3 polyunsaturated fatty acid content and mortality risk in hemodialysis patients. J Ren Nutr 2008;18:509-512.

6 Kutner NG, Clow PW, Zhang R, Aviles X: Association of fish intake and survival in a cohort of incident dialysis patients. Am J Kidney Dis 2002;39:1018-1024.

7 Friedman A, Watkins B, Li Y, Tamez H, Thadhani R: Exploratory study of the relationship between long chain omega-3 polyunsaturated fatty acids and sudden cardiac death in hemodialysis (abstract). JASN 2008; 19:492A.

$>8$ Svensson M, Schmidt E, Jorgensen K, Christensen J: n-3 fatty acids as secondary prevention against cardiovascular events in patients who undergo chronic hemodialysis: a randomized, placebo-controlled intervention trial. Clin J Am Soc Nephrol 2006; 1: 780-786.
-

Yoshimoto-Furuie K, Yoshimoto K, Tanaka T, Saima S, Kikuchi Y, Shay J, Horrobin DF, Echizen H: Effects of oral supplementation with evening primrose oil for six weeks on plasma essential fatty acids and uremic skin symptoms in hemodialysis patients. Nephron 1999;81:151-159.

10 Ristic V, Tepsic V, Ristic-Medie D, Perunicic G, Rasic Z, Postic M, Arsic A, BlazencicMladenovic V, Ristic G: Plasma and erythrocyte phospholipid fatty acids composition in Serbian hemodialyzed patients. Ren Fail 2006;28:211-216.

-11 Friedman A, Moe S, Perkins S, Li Y, Watkins B: Fish consumption and omega-3 fatty acid status and determinants in long-term hemodialysis. Am J Kidney Dis 2006;47:1064-1071.

12 Dasgupta A, Kenny MA, Ahmad S: Abnormal fatty acid profile in chronic hemodialysis patients: possible deficiency of essential fatty acids. Clin Physiol Biochem 1990;8: 238-243.

13 Peck LW, Monsen ER, Ahmad S: Effect of three sources of long-chain fatty acids on the plasma fatty acid profile, plasma prostaglandin E2 concentrations, and pruritus symptoms in hemodialysis patients. Am J Clin Nutr 1996;64:210-214.

14 Mozaffarian D, Rimm EB: Fish intake, contaminants, and human health: evaluating the risks and the benefits. JAMA 2006;296: 1885-1899.

15 Stipanuk M: Biochemical and Physiological Aspects of Human Nutrition, ed 1. Philadelphia, W.B. Saunders, 2000.

16 Li Y, Seifert MF, Lim SY, Salem N Jr, Watkins BA: Bone mineral content is positively correlated to n-3 fatty acids in the femur of growing rats. Brit J Nutr 2010;104:674-685.

17 U.S. Renal Data System, USRDS 2008 Annual Data Report: Atlas of End-Stage Renal Disease in the United States. Bethesda, National Institutes of Health, National Institute of Diabetes and Digestive and Kidney Diseases, 2008.
18 Maruyama C, Yoneyama M, Suyama N, Yoshimi K, Teramoto A, Sakaki Y, Suto Y, Takahashi K, Araki R, Ishizaka Y, Yamakado M, Teramoto T: Differences in serum phospholipid fatty acid compositions and estimated desaturase activities between Japanese men with and without metabolic syndrome. J Atheroscler Thromb 2008;15:306-313.

19 Hjartaker A, Lund E, Bjerve KS: Serum phospholipid fatty acid composition and habitual intake of marine foods registered by a semiquantitative food frequency questionnaire. Eur J Clin Nutr 1997;51:736-742.

-20 Hodge AM, English DR, O’Dea K, Sinclair AJ, Makrides M, Gibson RA, Giles GG: Plasma phospholipid and dietary fatty acids as predictors of type 2 diabetes: interpreting the role of linoleic acid. Am J Clin Nutr 2007; 86:189-197.

-21 Ohrvall M, Tengblad S, Vessby B: Tocopherol concentrations in adipose tissue. Relationships of tocopherol concentrations and fatty acid composition in serum in a reference population of Swedish men and women. Eur J Clin Nutr 1994;48:212-218.

-22 Steffen BT, Steffen LM, Tracy R, Siscovick D, Jacobs D, Liu K, He K, Hanson NQ, Nettleton JA, Tsai MY: Ethnicity, plasma phospholipid fatty acid composition and inflammatory/ endothelial activation biomarkers in the Multi-Ethnic Study of Atherosclerosis (MESA). Eur J Clin Nutr 2012;66:600-605.

23 Wu JH, Lemaitre RN, King IB, Song X, Sacks FM, Rimm EB, Heckbert SR, Siscovick DS, Mozaffarian D: Association of plasma phospholipid long-chain omega-3 fatty acids with incident atrial fibrillation in older adults: the cardiovascular health study. Circulation 2012;125:1084-1093.

24 Wang L, Folsom AR, Eckfeldt JH: Plasma fatty acid composition and incidence of coronary heart disease in middle aged adults: the Atherosclerosis Risk in Communities (ARIC) study. Nutr Metab Cardiovasc Dis 2003; 13:256-266. 
25 Asciutti-Moura LS, Guilland JC, Fuchs F, Richard D, Klepping J: Fatty acid composition of serum lipids and its relation to diet in an elderly institutionalized population. Am J Clin Nutr 1988;48:980-987.

-26 Rodriguez-Palmero M, Lopez-Sabater MC, Castellote-Bargallo AI, de la Torre-Boronat MC, Rivero-Urgell M: Administration of low doses of fish oil derived n-3 fatty acids to elderly subjects. Eur J Clin Nutr 1997;51:554560.

-27 Baylin A, Kim MK, Donovan-Palmer A, Siles X, Dougherty L, Tocco P, Campos H: Fasting whole blood as a biomarker of essential fatty acid intake in epidemiologic studies: comparison with adipose tissue and plasma. Am J Epidemiol 2005; 162:373-381.

-28 Sun Q, Ma J, Campos H, Hankinson SE, Hu FB: Comparison between plasma and erythrocyte fatty acid content as biomarkers of fatty acid intake in US women. Am J Clin Nutr 2007;86:74-81.
29 Hodson L, Skeaff CM, Fielding BA: Fatty acid composition of adipose tissue and blood in humans and its use as a biomarker of dietary intake. Prog Lipid Res 2008;47:348380.

30 Kris-Etherton PM, Harris WS, Appel LJ: Fish consumption, fish oil, omega-3 fatty acids, and cardiovascular disease. Circulation 2002;106:2747-2757.

31 Noori N, Dukkipati R, Kovesdy CP, Sim JJ, Feroze U, Murali SB, Bross R, Benner D, Kopple JD, Kalantar-Zadeh K: Dietary omega-3 fatty acid, ratio of omega- 6 to omega-3 intake, inflammation, and survival in longterm hemodialysis patients. Am J Kidney Dis 2011;58:248-256.

32 Dietary reference intakes for energy, carbohydrates, fiber, fat, fatty acids, cholesterol, protein, and amino acids. Washington, Institute of Medicine of the National Academies, 2005, pp 422-521.
33 U.S. Renal Data System, USRDS 2012 Annual Data Report: Atlas of End-Stage Renal Disease in the United States. Bethesda, National Institutes of Health, National Institute of Diabetes and Digestive and Kidney Diseases, 2012.

34 Svensson M, Christensen JH, Solling J, Schmidt EB: The effect of $n-3$ fatty acids on plasma lipids and lipoproteins and blood pressure in patients with CRF. Am J Kidney Dis 2004;44:77-83.

35 Mozaffarian D, Wu JH: Omega-3 fatty acids and cardiovascular disease: effects on risk factors, molecular pathways, and clinical events. J Am Coll Cardiology 2011;58:2047-2067.

36 K/DOQI Clinical Practice Guidelines for Cardiovascular Disease in Dialysis Patients. Am J Kidney Dis 2005;45:S91-S94.

37 Chan KE, Maddux FW, Tolkoff-Rubin N, Karumanchi SA, Thadhani R, Hakim RM: Early outcomes among those initiating chronic dialysis in the United States. Clin J Am Soc Nephrol 2011;6:2642-2649. 